\title{
The Productive Landscape in the Desert Margin for the Sustainable Development of Rural Settlements: An Innovative Greenbelt for Maranjab Desert in Iran
}

\author{
Mahnaz Sarlak $^{1}$ (D), Laura Valeria Ferretti ${ }^{2}$ (D) and Rita Biasi ${ }^{3, *(D)}$ \\ 1 Department of Architecture and Design and Ph.D. Program in Landscape and Environment, \\ Sapienza University of Rome, 00185 Rome, Italy; mahnaz.sarlak@uniroma1.it \\ 2 Department of Architecture and Design, Sapienza University of Rome, 00185 Rome, Italy; \\ lauravaleria.ferretti@uniroma1.it \\ 3 Department for Innovation in Biological Agrofood and Forest Systems, Tuscia University, 01100 Viterbo, Italy \\ * Correspondence: biasi@unitus.it
}

check for updates

Citation: Sarlak, M.; Ferretti, L.V.; Biasi, R. The Productive Landscape in the Desert Margin for the Sustainable Development of Rural Settlements: An Innovative Greenbelt for Maranjab Desert in Iran. Sustainability 2021, 13, 2077. https://doi.org/ $10.3390 /$ su13042077

Academic Editor: Jacques Teller

Received: 27 January 2021

Accepted: 10 February 2021

Published: 15 February 2021

Publisher's Note: MDPI stays neutral with regard to jurisdictional claims in published maps and institutional affiliations.

Copyright: (C) 2021 by the authors Licensee MDPI, Basel, Switzerland. This article is an open access article distributed under the terms and conditions of the Creative Commons Attribution (CC BY) license (https:// creativecommons.org/licenses/by/ $4.0 /)$.
Abstract: About two billion rural individuals depend on agricultural systems associated with a high amount of risk and low levels of yield in the drylands of Asia, Africa, and Latin America. Human activities, climate change and natural extreme events are the most important drivers of desertification. This phenomenon has occurred in many regions of Iran, particularly in the villages in the periphery of the central desert of Iran, and has made living in the oases so difficult that the number of abandoned villages is increasing every year. Land abandonment and land-use change increase the risk of desertification. This study aims to respond to the research questions: (i) does the planning of green infrastructures on the desert margin affect the distribution and balance of the population? (ii) how should the green belt be designed to have the greatest impact on counteracting desertification?, and (iii) does the design of productive landscape provide the solution? Through a wide-ranging and comprehensive approach, this study develops different scenarios for designing a new form of green belt in order to sustainably manage the issues of environmental protection, agricultural tradition preservation and desertification counteraction. This study proposes a new-traditional greenbelt including small low-cost and low-tech projects adapted to rural scale.

Keywords: artificial groundwater recharge; cultural landscape; desertification; land-use changes; multifunctional agriculture; oasification; rural-urban migration; soil degradation; traditional agricultural practices

\section{Introduction}

Living in the desert margin implies the necessity to deal with several challenges in a changing environment. Rural settlements must guarantee the inhabitants agriculture for local supply, environmental quality and well-being [1], while at the same time fighting the phenomenon of desertification. In desert and semi-desert areas, the short rainy season provides a limited opportunity for plant growth, especially food plants, and water scarcity is frequently coupled with soil salinity, which is not even less dangerous for plant growth [2]. Nonetheless, traditional agriculture over centuries has developed practices that enable farmers to better manage water resources and low soil fertility [3]. Traditional agricultural systems are the result of centuries of indigenous peoples' experience of adapting to arid environmental conditions [4]. Apart from natural factors, human factors play an important role in desertification [5]. With several centuries of poor management of natural resources and increasing anthropogenic pressures associated with rapid population growth, the degradation of natural resources, especially vegetation, and the abandonment of rural areas in favor of cities have caused the progressive advance of desertification [6].

In recent years, with increasing climate variability, migration [7] and urbanization phenomena [8], Iran has faced problems in the implementation of long-term development 
plans, as well as the failure to comply with urban development plans and rural plans $[9,10]$. Because of the conflicting trade and agricultural policies pursued by governments, the failure of governments to involve the people who are affected and the lack of local support, many plans to combat desertification are undermined [11].

Several strategies worldwide are being undertaken to physically counteract the phenomenon of desert advance, such as the green walls [12], as a tool for assuring the resilience of housing settlements together with traditional rural culture preservation and sustainable land planning. In arid and semi-arid regions, the green belt is known as the afforestation project to combat desertification and land degradation by planting trees on the edge of a desert.

The reforestation/afforestation options, as the large-scale implementation activities of planting trees, are used to generate favorable atmospheric circulation patterns for enhanced precipitation and evapotranspiration favorable to the regional climate [13]. Many afforestation projects on the edge of the desert have failed [14]. For example, the project of "Forestry I" in Nigeria was designed in 1979 and it was aborted in 1984. "Seedlings survivals rate was very low. Only less than 5 percent of over 50 million seedlings distributed free of charge during the five years survived [15]." Furthermore, Joseph Stalin launched a similar effort in the 1940s, planting more than 10,000 square miles of steppe land with trees; almost all of them were dead within 20 years [16]. From the unsuccessful experiences of these projects, useful lessons have been learned for future projects. In 2007, the definition of the African Great Green Wall was changed from a wall of trees to a great mosaic of green and productive landscapes $[17,18]$. Based on this new concept, various methods for creating a sustainable green landscape in desert areas have been considered and researched.

Indeed, one of the most important models for achieving sustainable development in desert rural areas is to keep the population in place and preserve the settlements, together with the resilience of agriculture. It is, therefore, necessary to find solutions that involve local communities in the fight against desertification through an in-depth study on the mechanisms of desertification and the lack of water resources in the settlements on the edge of the desert.

The process of recognizing, protecting, and restoring rural landscapes is a complex research field that creates a link between culture, physical environment, and ecological systems [19].

This study aims to investigate and formulate a strategic model for balancing the distribution of settlement in desert areas in addition to preserving traditional agricultural culture. This research aims to demonstrate that by using the existing agricultural potential in the region, reinforcing it, and adapting it to contemporary times through the definition of a new productive oasis, the consolidation of existing settlements, the relaunch of abandoned villages, and the creation of jobs, many migrations can be stopped and even reversed.

This research, with a wide-ranging and comprehensive approach, develops different scenarios for designing a new form of green belt in order to sustainably manage the issues of environmental protection, agricultural tradition preservation and desertification counteraction.

\section{Materials and Methods}

\subsection{The Study Site}

The research has been carried out in the margin of Maranjab Desert in Iran (Figure 1). In the Maranjab desert, which is located between Kashan and Salt Lake, there is one of the complexes of sand dunes called Band-e-Rig or Rig-Boland. The sandy hills form a halfmoon, from south-east to north-west, about $120 \mathrm{~km}$ long and $25 \mathrm{~km}$ wide on average. It is between 800 and $1000 \mathrm{~m}$ a.s.l. The Band-e-Rig hill, with a height of $100 \mathrm{~m}$, is one of the most important elements in the natural landscape structure of the study area (Figure $1 \mathrm{~b}$ ). The study area is represented by the intersection of Aran-Bidgol county (as the administrative boundary) and Kashan watershed (as the natural boundary) (Figure 2). 


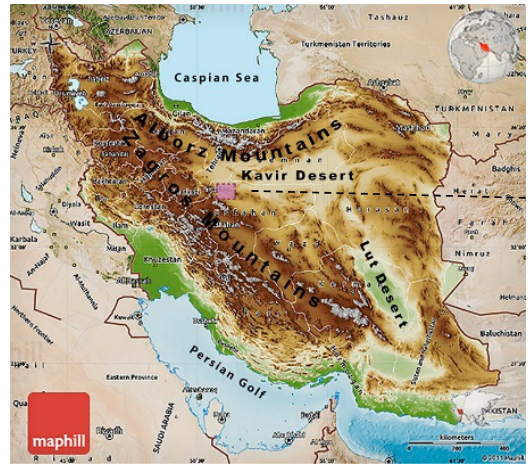

(a)

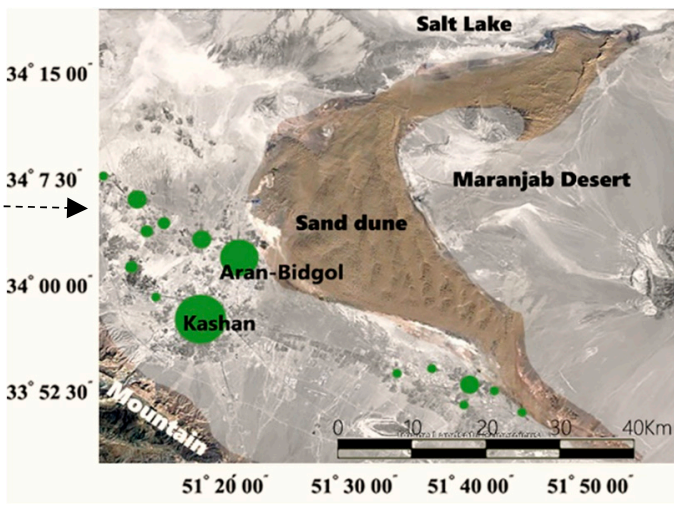

(b)

Figure 1. The location of the study area: (a) Iran's topography map @ $\mathrm{www}$.maphill.com, Accessed on 10 April 2019; (b) the main natural elements (including mountain, sand dune, Salt Lake) and the big oases (green circles) in the study area of the Maranjab Desert.
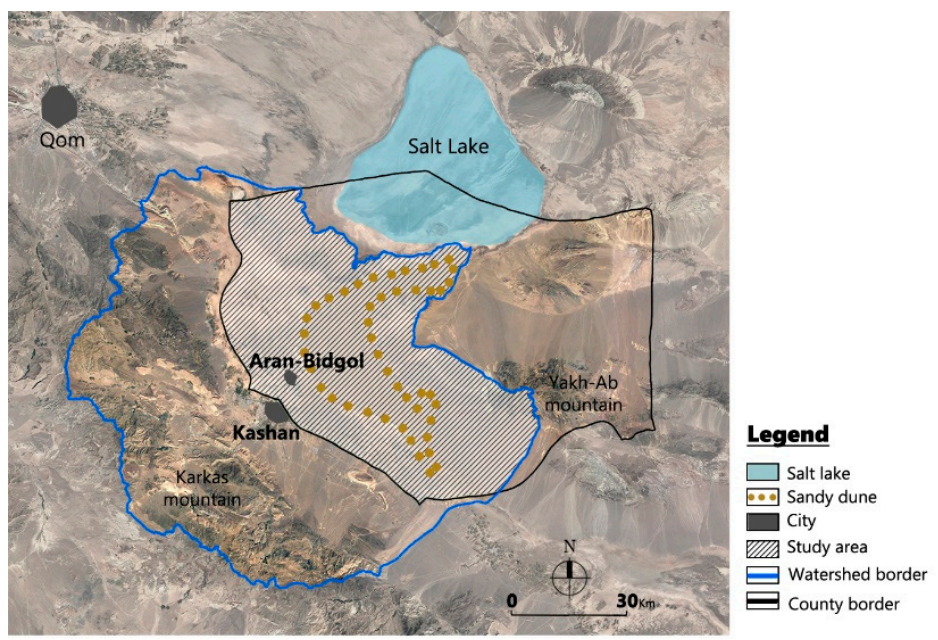

Figure 2. The delimitation of the study area.

The presence of the sand dunes has defined a natural boundary and limit in the region, which has hindered the expansion of the settlements. A collection of oases has been formed in the plain between the sand dunes and the mountainous region (Figure 3).

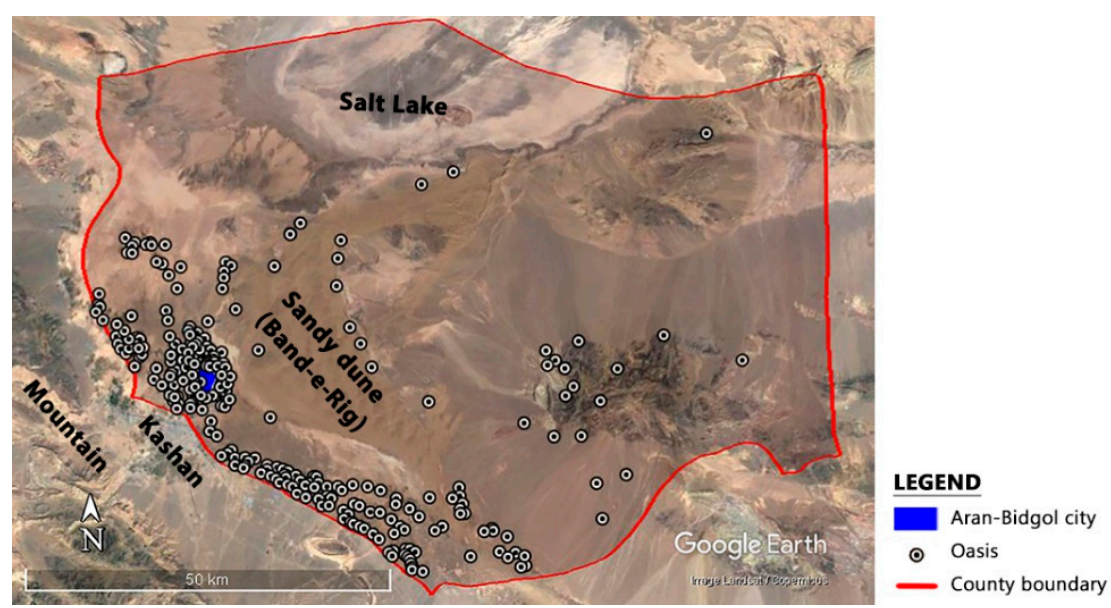

Figure 3. The Distribution of Oases (geographical coordinates of oases received from Forest, Range and Watershed Organization F.R.W.O., map by using GIS, google earth, Photoshop). 
The presence of underground water resources was the main factor for the emerging initial core of the cities and their physical growth and development [20]. Qanats are the traditional "subterranean tunnel-well" [21], whose structure is a set of two major parts:

- A low-sloped underground horizontal channel from the foothills to the plain, which directs water from the groundwater table to the surface;

- A series of vertical wells that are used to ventilate the horizontal channel and also remove the excavated soil during the qanat construction from the underground, as well as the repair and restoration of the qanat (Figure 4).

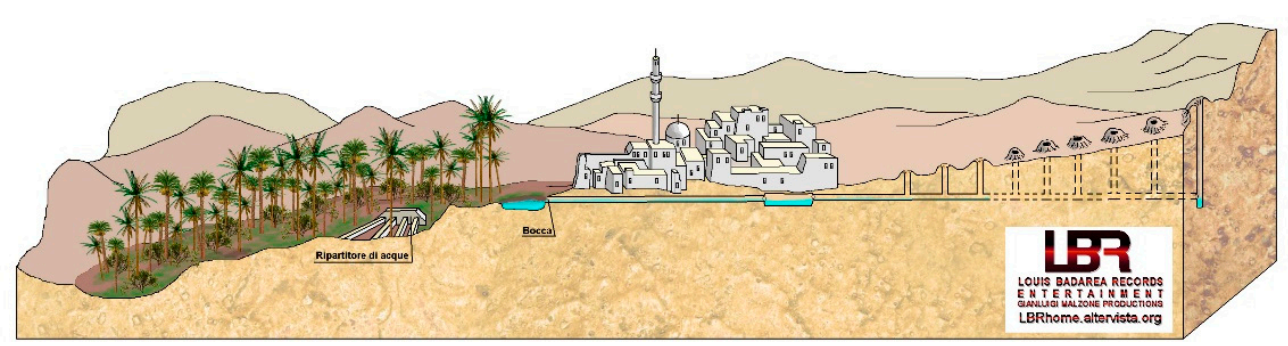

Figure 4. The section of qanat system and the passage of water through residential areas and farms (source: http:/ /lbrhome.altervista.org/antichi-acquedotti-qanat-e-foggara, Accessed on 15 June 2020).

Qanats, by transferring water from the mountain to dry areas, have played a major role in the formation and development of settlements in the desert and semi-desert areas of Iran [22]. The general landscape in the study area consists of a series of scattered oases. Each oasis consists of one village and agricultural land that expanded according to the number and quality of available water resources [23].

In this area, agriculture is based on family traditional farming. Due to the scarcity of water resources and poor soil quality, the extent of the farmlands is often small. Agriculture in this region, like in other regions in the margin of the central desert of Iran, has been performed by using water from qanats and flood irrigation [24], but today, in most cases, deep wells and drip irrigation have replaced traditional methods. Despite modern changes in lifestyle and agriculture, some special traditional farming methods are still active in this area, which, with simple but effective methods, play an important role in combating desertification. So, it is an important issue to find a way to adapt and integrate local traditional practices into modern technologies [3].

\subsection{Logical Framework}

Given the multipurpose scope of the research due to its interdisciplinary nature, the descriptive survey aimed to obtain a better awareness of existing conditions and to assist in the decision-making process. The adopted approach was developed in three steps:

\subsubsection{Research Hypotheses and Landscape Analysis}

Political, social, and economic changes have a strong impact on the transformation of rural areas proximal to the desert. The processes of industrialization of large urban centers absorb the rural labor force and influence the social and cultural structure of rural heritage [25]. This affects social behavior and activity, as well as the visual rural landscape. Today, rural and agricultural landscapes are undergoing social and economic transformations [26]. Compared to traditional agricultural land management, which has been standing for centuries, the development of modern agrosystems does not seem to determine resilience [27]. With the onslaught of industrial agriculture and urbanization and with the spread of such phenomena as land-use change and agricultural land abandonment, traditional agricultural landscapes, and the related biological and cultural diversity, are rapidly disappearing $[28,29]$. Land-use change from rural and agricultural to urban and industrial is an unsustainable development that has increased the risk of desertification [30]. 
In this context, landscape and land-use changes in the study area were studied by collecting the official data and documents, which are listed in Table 1.

Table 1. List of official documents.

\begin{tabular}{ccc}
\hline Document/Data & Year & Official Sources \\
\hline Topography map & 2017 & $\begin{array}{c}\text { Iran National Cartographic Center } \\
\text { Iran's National Geographical } \\
\text { Organization }\end{array}$ \\
$\begin{array}{c}\text { Aerial photo } \\
\text { Agricultural zones map }\end{array}$ & 1955 & $\begin{array}{c}\text { Iran's National Geographical } \\
\text { Organization }\end{array}$ \\
$\begin{array}{c}\text { Prescription plains for drilling new } \\
\text { wells }\end{array}$ & 1974 & $\begin{array}{c}\text { Regional Water company of Isfahan } \\
\text { Statistical Center of Iran (available in } \\
\text { https://www.amar.org.ir/, Accessed } \\
\text { on 20 July 2018) }\end{array}$ \\
\hline
\end{tabular}

Furthermore, actual land use/cover was assessed through the interpretation of recorded observations by unmanned aerial photography (fly date May 2018).

The research question was formulated: does a productive landscape represent a land system able to counteract desertification and strengthen settlements' resilience?

\subsubsection{Hypotheses Testing}

In order to confirm the hypotheses based on the effect of land-use change on the intensification of desertification, it was necessary to determine the intensity of desertification in the study area. To implement a survey method, the IMDPA model was used (Iranian Model of Desertification Potential Assessment). The basis of the IMDPA model is the MEDALUS [31] model (Mediterranean Desertification and Land Use, European commission 1999). In the MEDALUS model, 6 main factors or indicators of desertification, including soil, climate, erosion, plant cover, groundwater and management, were considered for evaluation. The IMDPA model consists of 9 criteria and 36 indices to evaluate desertification. The nine criteria include climate, geology and geomorphology, soil, vegetation, water, erosion, agriculture, socio-economic issues, industrial and civil development [32]. This model evaluates status and desertification potential simultaneously, without discriminating either of them. In order to combine indices into criteria and finally desertification risk, geometric averaging is used [33].

In this research, soil and water criteria were considered and measured. The indicators related to the soil are based on: (i) Electrical Conductivity (EC), (ii) depth, and (iii) the texture of the soil; while those related to water are based on: (i) Electrical Conductivity (EC), (ii) Sodium Absorption Ratio (SAR), and (iii) groundwater level. For the study area, data were collected and analyzed and interpreted according to the IMPDA score table. A total of 14 samples of water and 18 samples of agricultural soil were collected (Figure 5) in the study area. The information of the depth of soil was kindly provided by the Soil and Water Research Institute (http:/ / www.swri.ir/, Accessed on 14 May 2018) and the groundwater level data were kindly provided by the Water Research Institute of Iran (https:/ /www.wri.ac.ir/, Accessed on 16 May 2018). 


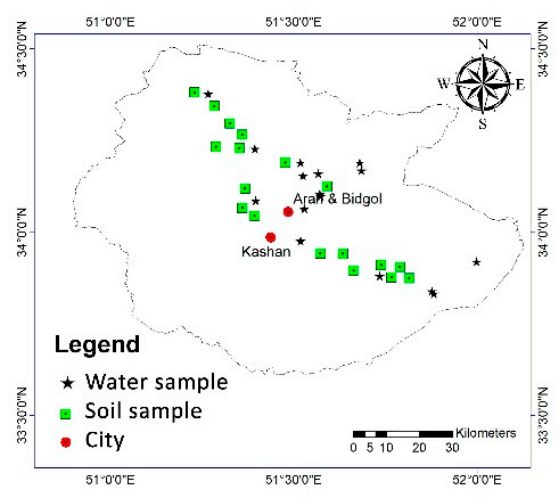

Figure 5. Location of water and soil sampling in Kashan watershed (April 2018).

To collect samples of water, the wells were selected according to the size of the study area, topographic conditions and based on agricultural use. Electrical Conductivity was calculated by EC-meter and Sodium Absorption Ratio (SAR) was calculated by measuring $\mathrm{Na}, \mathrm{Ca}, \mathrm{Mg}$ and using the formula (Table S1). The formula for calculating the Sodium Adsorption Ratio (SAR) is:

$$
S A R=\frac{N a^{+}}{\sqrt{\frac{1}{2}\left(\mathrm{Ca}^{2+}+M g^{2+}\right)}}
$$

Then, each water index was scored according to the IMDPA classification (Table 2), and finally, using the following relation, the water criterion map was calculated.

$$
Q_{W}=\sqrt[3]{Q_{W 1} \times Q_{W 2} \times Q_{W 3}}
$$

$Q_{W}:$ Qualitative water

$Q_{W 1}$ : Electrical Conductivity (EC)

$Q_{W 2}$ : Sodium Adsorption Ratio (SAR)

$Q_{W 3}$ : Declining groundwater levels

Table 2. The weight of water index in the Iranian Model of Desertification Potential Assess-

\begin{tabular}{|c|c|c|c|c|c|}
\hline \multirow[b]{2}{*}{ Desertification Classes } & $<1$ & $1-1.5$ & $1.6-2.5$ & $2.6-3.5$ & $3.6-4$ \\
\hline & Very Low & Low & Medium & High & $\begin{array}{l}\text { Very } \\
\text { High }\end{array}$ \\
\hline $\mathrm{EC}(\mu \mathrm{s} / \mathrm{cm})$ & $<250$ & $250-750$ & $2250-750$ & $5000-2250$ & $\geq 5000$ \\
\hline $\mathrm{SAR}(\mathrm{meq} / \mathrm{L})$ & $<10$ & 10-18 & 26-18 & $32-26$ & $\geq 32$ \\
\hline $\begin{array}{c}\text { Groundwater Decline } \\
(\mathrm{cm} / \text { year })\end{array}$ & $<10$ & $10-20$ & $30-20$ & $50-30$ & $\geq 50$ \\
\hline
\end{tabular}
ment (IMDPA).

The sampling of soil was carried out at 18 points (Figure 5) of arable land in the study area, including farms, abandoned farms, and rangelands. Determining soil texture in this study is based on USDA (United States Department of Agriculture) classification by the Hydrometer Method [34]. Besides soil texture, the main chemical soil traits were determined ( $\left.\mathrm{pH}, \mathrm{Ec}, \mathrm{CaCO}_{3}, \mathrm{~N}, \mathrm{P}, \mathrm{K}\right)$.

Then, each soil index was scored according to the IMDPA classification (Table 3), and finally, using the following relation, the soil criterion map was calculated.

$$
Q_{S}=\sqrt[3]{Q_{S 1} \times Q_{S 2} \times Q_{S 3}}
$$

$Q_{S}:$ Qualitative soil 
$Q_{S 1}$ : Electrical Conductivity (EC)

$Q_{S 2}$ : Soil texture

$Q_{S 3}$ : Depth of soil

Table 3. The weight of soil index in the IMDPA model.

\begin{tabular}{cccccc}
\hline $\begin{array}{c}\text { Desertification } \\
\text { Classes }\end{array}$ & $\begin{array}{c}<\mathbf{1} \\
\text { Very Low }\end{array}$ & $\begin{array}{c}\mathbf{1 - 1 . 5} \\
\text { Low }\end{array}$ & $\begin{array}{c}\mathbf{1 . 6 - 2 . 5} \\
\text { Medium }\end{array}$ & $\begin{array}{c}\mathbf{2 . 6 - 3 . 5} \\
\text { High }\end{array}$ & $\begin{array}{c}\mathbf{3 . 6 - 4} \\
\text { Very High }\end{array}$ \\
\hline EC $(\mathrm{ds} / \mathrm{m})$ & $<2$ & $2-4$ & $4-8$ & $8-16$ & $\geq 16$ \\
Depth $(\mathrm{cm})$ & $>110$ & $80-110$ & $50-80$ & $20-50$ & $<20$ \\
Soil texture & Clay & Clay loam & Loam & Sandy loam & Sandy \\
\hline
\end{tabular}

Finally, two criteria of soil and water were combined as follows:

$$
Q_{D}=\sqrt[2]{Q_{S} \times Q_{W}}
$$

$Q_{D}$ : Desertification sensitivity

$Q_{S}$ : Qualitative soil

$Q_{W}$ : Qualitative water

The spatialization of the obtained results was integrated and processed in the ArcGIS software as an information level. The corresponding maps were synthesized using the medium geometric method, producing a final desertification map of the Kashan watershed based on the IMDPA model. Using ArcGIS, AutoCAD, and Photoshop software, the data were analyzed to determine the severity of desertification in the study area and to allow the identification of the site of the proposed strategy of intervention, the most sensible one.

\subsubsection{Scenario Design}

The proper effectiveness of today's decisions is fully related to future situations. "Scenario-based investigations of possible futures have been used since the middle of the 20th century to help decisionmakers cope with alternative courses of action and elements of uncertainty. Since the early 1970s, they have been increasingly used for landscape planning. Each scenario-based study is founded on assumptions of possible change" [35]. Most conceptions of scenarios share four principles:

- $\quad$ scenarios represent a process of change over some duration;

- scenarios describe situations, actions, and consequences which are contingently related;

- scenarios are understood to be predictive judgments which describe what could happen, not predictions which describe what will happen, or even what is likely to happen;

- $\quad$ scenarios organize information within explicitly defined frameworks" [35].

The probable futures of the desert margin landscape have been examined in 3 scenarios:

- Scenario 1: Evolution of current conditions. In this regard, 3 very important and effective projects have been selected: (i) Comprehensive planning (2013); (ii) Tourism route planning (2011); (iii) Afforestation (combat to desertification projects through biological stabilization by planting Haloxylon trees implemented in Aran-Bidgol county, last update 2018). In the following, the main idea of each project and its effects on landscape changes are examined.

- Scenario 2: Reconstruction of the past. This scenario is based on the hypothesis of the resettlement of rural areas by the preservation and restoration of existing cultural heritage, such as qanats and small settlements, together with technological innovation for water supply.

- Scenario 3: New-traditional spatial configuration. This scenario is based on a landscape architecture project that implies the reorganization of the rural and agricultural landscape in the desert margin as a barrier against desertification leading to a new oasification. 
In each scenario, based on the strengths, weaknesses, threats and potentials, the possible solutions in terms of landscape design to combat desertification are analyzed.

Finally, a new-traditional model of green belts consisting of various land-uses is proposed.

\section{Results and Discussion}

The results of the investigation in the study area and the landscape design projects proposed for the case study under different scenarios are reported.

\subsection{Landscape Analysis}

The research area is plain with a gentle slope from south to north, and as we approach the desert and the north, it gets closer to flat conditions with a plain topography due to moving away from the foothills-mountainous area (Figure S1).

This gentle slope and the earth's smooth terrain have provided a suitable ground for agricultural activity and oases. Most of the villages and cities are located in the plain between the highlands in the southwest of Aran-Bidgol county and sand dunes (Figure 6). Due to the existence of railways and two highways, the study area has quick access to large cities such as Tehran and Isfahan.

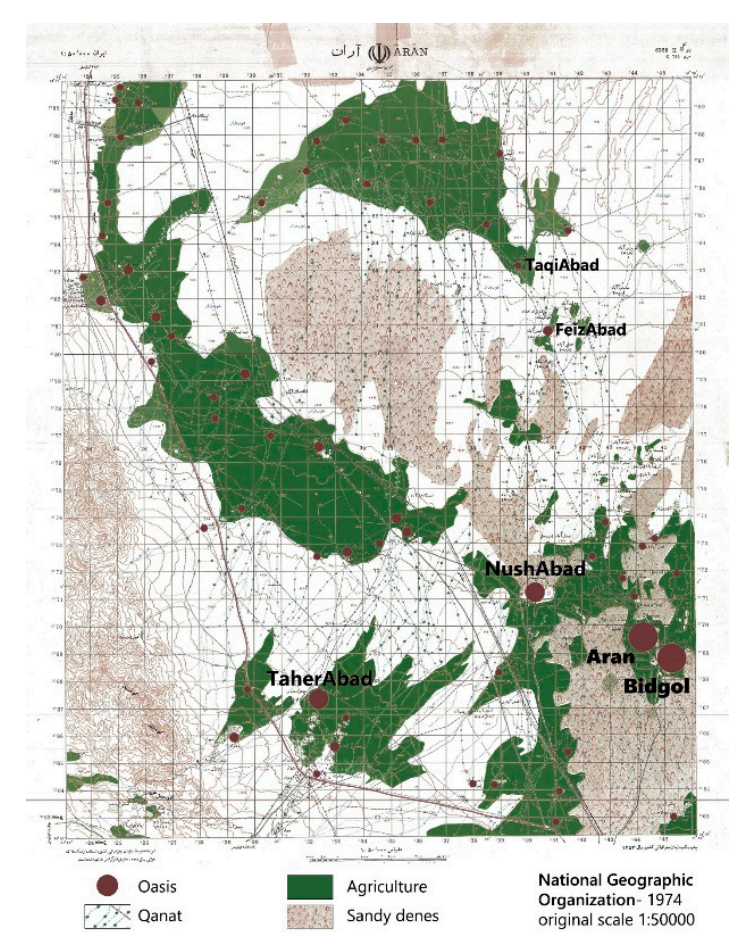

Figure 6. Location of oases and agricultural areas (map received from Iran's National Geographical Organization, based on aerial photos 1974).

With 118 to 150 strands of qanats and with an average length of $12 \mathrm{~km}$ each, AranBidgol encompasses over $1680 \mathrm{~km}$ of cavities and water tunnels below itself, which indicates the importance of the water system distribution and the use of land in the farming and livelihood activities of this territory [36]. Until 1960, excavating wells was not common in rural regions of Iran, but with the start of modernity, the digging of wells started as one of the most important sources of drinking and farming water supply in these regions [37]. In desert areas, due to the low rainfall, high temperatures, and severe evaporation, the formation of groundwater aquifers and the natural recharge of the existing groundwaters is a very slow process. In such a situation, in case the extraction of groundwater is more than its recharge, the groundwater level of the aquifers will obviously be lowered and the result will be water salinity [38]. The reason for this is that as the freshwater in the underground aquifers declines, salty water will enter the wells. The salinization of these well waters 
and using them for irrigation make the soil become even saltier. In these situations, if the extraction of groundwater continues in an inappropriate trend, the water in deep wells will certainly become a factor in accelerating the desertification into the farmlands and pastureland [39]. In Iran, after 1976, the digging of the well was banned in the plains with the risk of groundwater resource decline such as Kashan watershed (Figure 7).

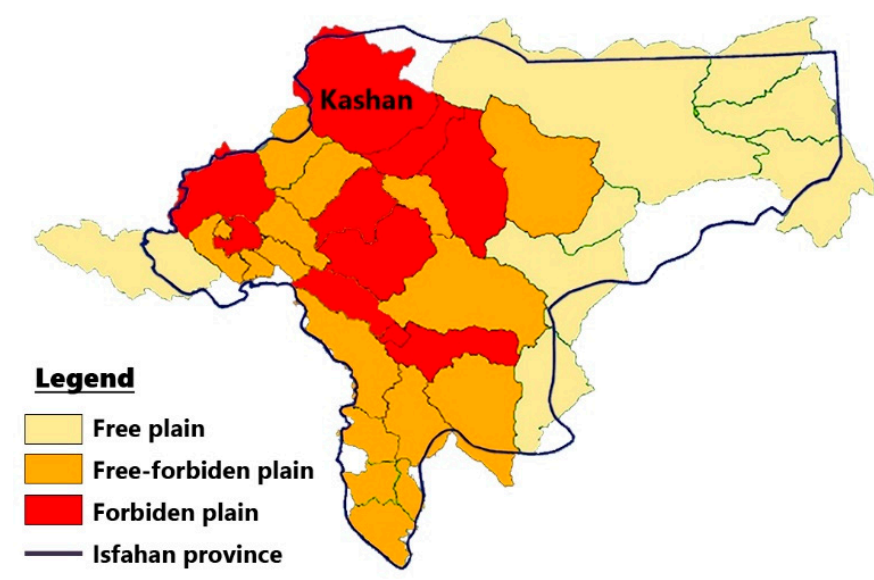

Figure 7. Prescriptive of Isfahan's plains for drilling the new deep well (Source: Regional Water Company of Isfahan Province, 2017).

Despite the ban on the exploitation of underground water due to the wasteful excavation of deep wells and excessive utilization, strong damage has occurred to the level of groundwater so that most of the qanats have dried and the yield of old wells has fallen sharply. Downstream oases gradually faced water scarcity, and people had two paths to survive: either migrating to upstream oases or excavating deeper wells. Due to the high cost of excavating deep wells and the small size of these villages, most of the villagers chose the migration option and settled in upstream oases (Table 4). Over time, many upstream villages were changed to cities. Population growth analysis (Table 4) also shows that rural population growth is much slower than urban population growth. Due to migration from rural to urban areas, most of the county's population growth is related to cities. It can be concluded that the younger population has decreased in the villages (Figure S2). Usually, urban residents, especially young people, although coming from villages, have less interest in continuing agricultural activity and in activities related to rural life. If this trend continues in the long run, most of the villages will be abandoned, and the rural and agricultural landscapes are at risk of destruction and disappearance (Figure 8).

Table 4. Quantitative changes of villages and population growth in urban and rural areas of AranBidgol county (Source: Statistical Center of Iran).

\begin{tabular}{ccccc}
\hline & Unit & $\mathbf{2 0 0 6}$ & $\mathbf{2 0 1 1}$ & $\mathbf{2 0 1 6}$ \\
\hline Village with inhabitants & number & 49 & 45 & 41 \\
Village without inhabitants & number & 61 & 65 & 69 \\
\hline Urban population & person & 76,438 & 82,332 & 89,022 \\
Rural population & person & 13,523 & 15,077 & 14,495 \\
Total population & person & 89,961 & 97,409 & 103,517 \\
\hline
\end{tabular}




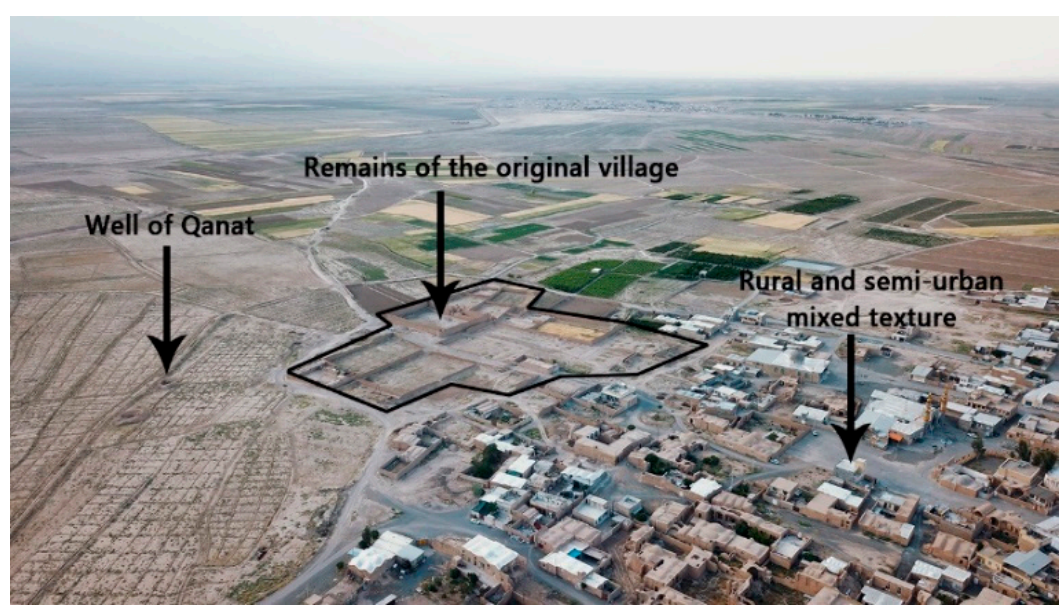

Figure 8. The rural landscape that is changing to an urban landscape (Taher-Abad, 2019, photo obtained by an unmanned aerial vehicle).

Due to the process of urbanization and industrialization, the agricultural landscape has undergone drastic changes [40] (Figure 9), so that the area of farmland has been drastically reduced (Table 5).
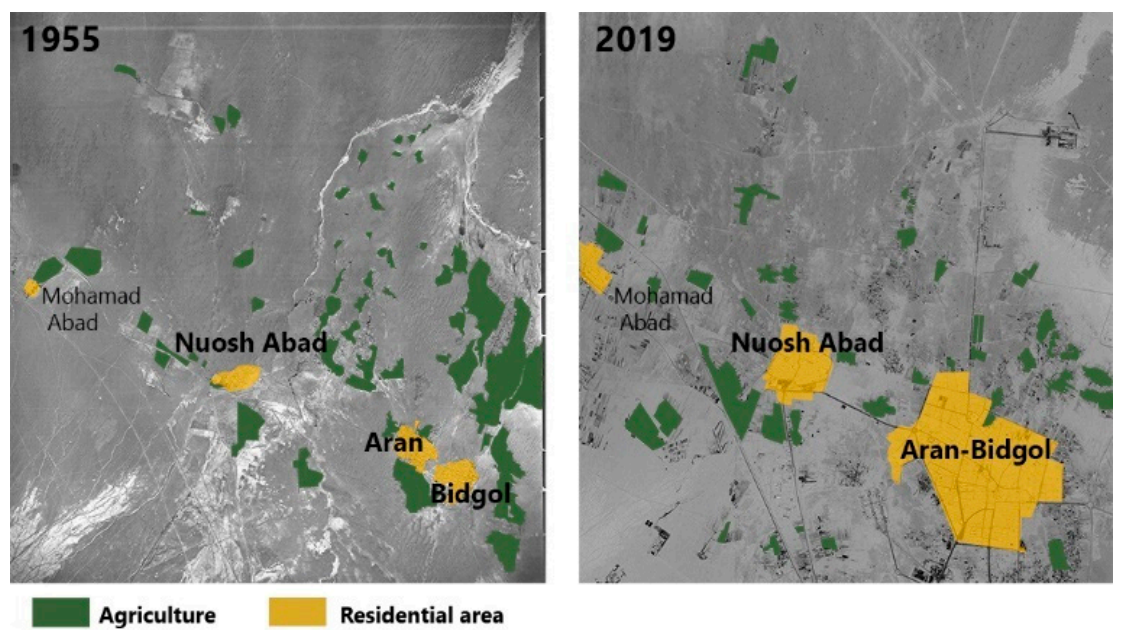

Figure 9. Changes in agricultural areas: (left) based on an aerial photo of 1955, received from Iran's National Geographic Organization; (right) based on google map 2019.

Table 5. Quantitative changes of the cultivated surfaces (in hectares) over time (Source: Organization Agriculture Jahad Isfahan, www.agri-es.ir, Accessed on 21 August 2019).

\begin{tabular}{ccccc}
\hline & $\mathbf{2 0 0 1}$ & $\mathbf{2 0 0 6}$ & $\mathbf{2 0 1 1}$ & $\mathbf{2 0 1 6}$ \\
\hline Farming areas & 10,227 & 11,004 & 10,397 & 8181 \\
Orchards & 1180 & 1561 & 2305 & 2256 \\
The total area of irrigated agriculture & 11,407 & 12,565 & 12,702 & 10,437 \\
\hline
\end{tabular}

The agricultural activities that are in this area can be divided into two main groups:

- Traditional or subsistence farming in the form of family farming, where the main crops are barley (Hordeum vulgare), wheat (Triticum spp), alfalfa (Medicago sativa), and melon (Cucumis melo);

- Semi-modern or commercial farming in the form of cooperative farming, where the main crop is pistachio (Pistacia vera). 
Due to changes in the cultivated area of main crops (Table 6), it can be concluded that traditional agriculture has declined, and commercial agriculture has increased.

Table 6. Quantitative changes of the cultivated area (in hectares) of each main crop over time (Source: Organization Agriculture Jahad Isfahan, www.agri-es.ir, Accessed on 23 August 2019).

\begin{tabular}{cccccc}
\hline \multirow{2}{*}{ Category } & \multirow{2}{*}{ Main Crop } & \multicolumn{4}{c}{ Area (ha) } \\
\cline { 3 - 6 } & & $\mathbf{2 0 0 1}$ & $\mathbf{2 0 0 6}$ & $\mathbf{2 0 1 1}$ & $\mathbf{2 0 1 6}$ \\
\hline \multirow{2}{*}{ Cereals } & Barley & 4000 & 4235 & 4700 & 3600 \\
& Wheat & 1900 & 1525 & 1400 & 800 \\
\hline \multirow{2}{*}{ Plants used in industry } & Cotton & 1148 & 1018 & 850 & 500 \\
\hline \multirow{2}{*}{ Forage } & Alfalfa & 700 & 350 & 600 & 919 \\
& Forage corn & 342 & 541 & 540 & 300 \\
\hline \multirow{2}{*}{ Kitchen garden } & Cantaloupe & 680 & 1169 & 1055 & 668 \\
& Melon & 385 & 347 & 350 & 177 \\
\hline \multirow{2}{*}{ Orchards } & Pistachio & 1100 & 1198 & 2065 & 1581 \\
& Olives & 30 & 123 & - & - \\
& Pomegranate & - & 97 & 235 & 195 \\
\hline
\end{tabular}

The disappearance of traditional agriculture is a warning because the traditional agricultural landscapes managed under the influence of local knowledge and culture have similar properties: they have production cycles that have little input, they are ecologically and economically sustainable, they bring together a variety of species and structures in time and place, and they create sustainable cycles through effective recycling measures [41], and they are also associated with special and unique qualities, such as health, purity of ecosystem, peace and originality [27]. The traditional agricultural landscape is a result of the survival and continuity of agricultural activities that have created a valuable cultural heritage- - a heritage that needs protection and transfers to future generations. Research on traditional agriculture shows that most indigenous modes of production exhibit a strong foundation and base, which leads to the creation of a landscape with stable vital cycles [42].

There are valuable examples of traditional agriculture in the study area (Figure 10) that needs to be more activated and protected, such as rainfed agriculture on sand dunes of the desert. It is based on a traditional technique of using underground water without the need to dig a well or even a channel. In fact, underground water is directly used in agriculture without any facilities. In this traditional agricultural system, the roots of the plants grow and reach the underground water, so they are not directly irrigated (Figure 11). Additionally, it is an excellent example of combating desertification by using abiotic windbreak (Figure 12).

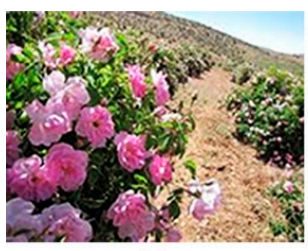

(a)

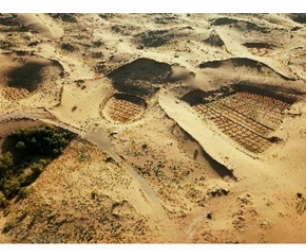

(b)

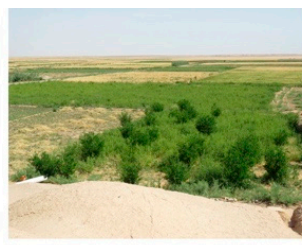

(c)

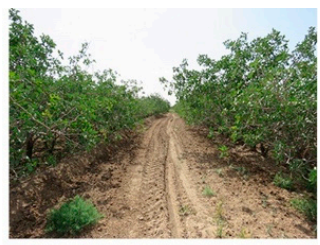

(d)

Figure 10. Traditional agricultural landscapes: (a) rose garden; (b) the farm pits on sand dunes; (c) polyculture; (d) pistachio orchards. All photos taken in 2018. 


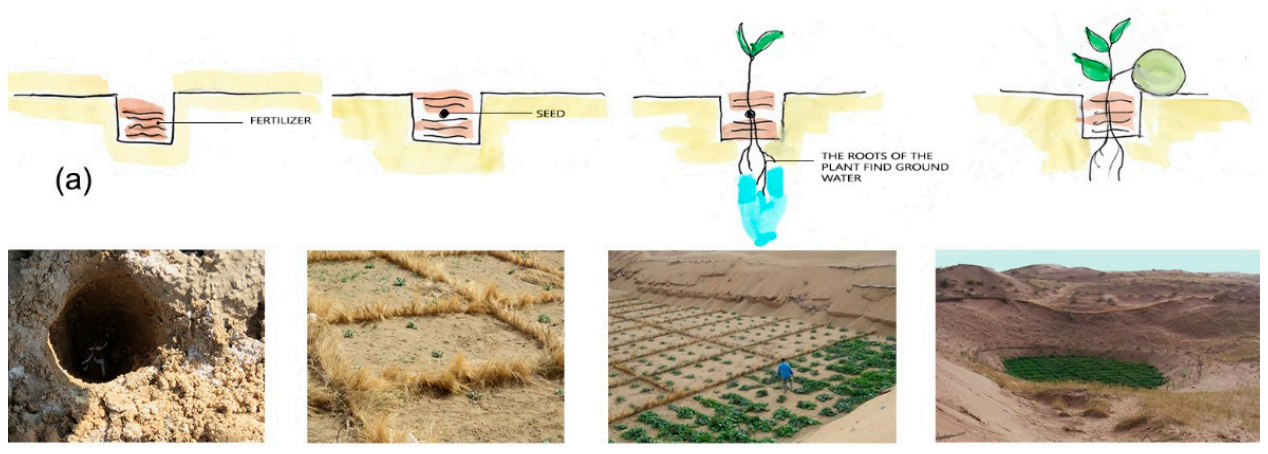

(b)

Figure 11. Growing steps from seeding to crop (cantaloupe): (a) sketch; (b) photos taken from March to July 2018.

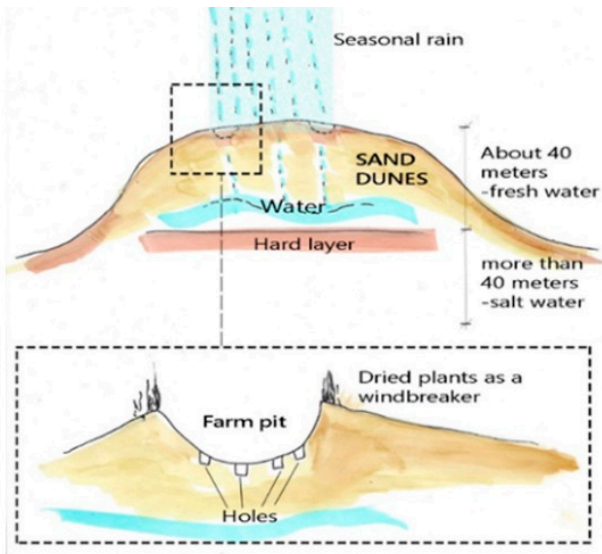

(a)

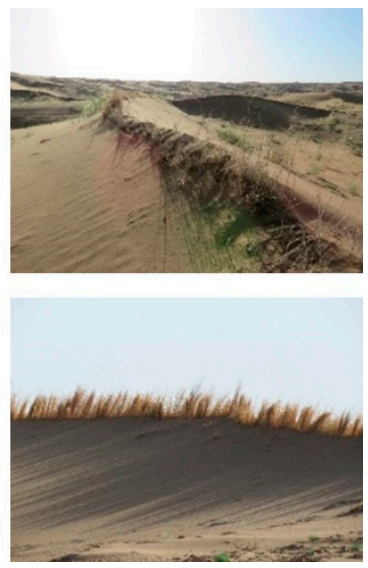

(b)

Figure 12. Agriculture as a method to combat desertification: (a) sketch of the farm pits on a sand dune and traditional water management; (b) dried plants as an abiotic windbreak (April 2018).

Polyculture is one of the important features of traditional agriculture, while unifying, eliminating crop diversity and species diversity and the diversity of land farms are the main attributes of industrial agriculture. Wherever there is no diversity, the ecosystem faces a risk of instability [28]. In addition to environmental problems, with the destruction of traditional agriculture and the migration of farmers to cities, new jobs are needed. The establishment of factories and the expansion of industrial zones are some of the most important land-use changes in the study area (Figure 13). The main industrial areas in the study area are listed below (Table 7). 


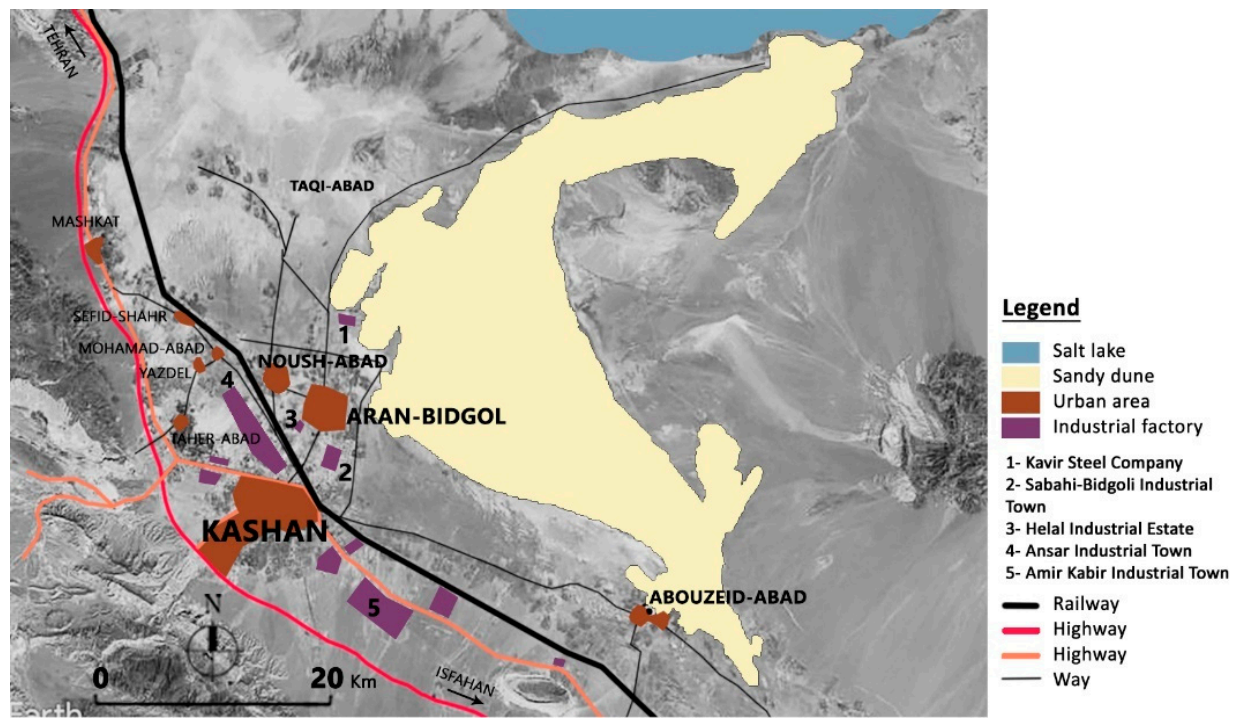

Figure 13. Industrial zones.

Table 7. The main industrial units [43].

\begin{tabular}{|c|c|c|c|}
\hline Name & $\begin{array}{l}\text { Establish } \\
\text { Date }\end{array}$ & Product & Area (ha) \\
\hline Kavir Steel Company & 2000 & Rebar, wire rod & 45 \\
\hline $\begin{array}{l}\text { Sabahi-Bidgoli } \\
\text { Industrial Town }\end{array}$ & 1990 & $\begin{array}{l}\text { Machine-made carpets, chemicals and } \\
\text { hygienic material production, home } \\
\text { dishes and appliances manufacturing } \\
\text { units, and motor pumps making units }\end{array}$ & 400 \\
\hline $\begin{array}{l}\text { Helal Industrial } \\
\text { Estate }\end{array}$ & 2003 & $\begin{array}{c}\text { Machine-made carpets, textile, } \\
\text { knitting industries }\end{array}$ & 57 \\
\hline
\end{tabular}

\subsection{The Severity of Desertification in the Study Area}

The desertification severity was assessed through the determination of water and soil quality traits. The results of the water quality assessment are reported in Table S1.

The soil quality of arable land in the study area (including active farms, abandoned farms, rangelands) was analyzed based on United States Department of Agriculture (USDA) classification by the Hydrometer Method and using the soil texture triangle. The resulting texture was mainly from sand to sandy-loam (Figure 14) (Table S2).

By combining the two criteria of water and soil, a map of sensitivity to desertification was produced in GIS software (Figure 15).

By comparing the desertification sensitivity map and the situation of large industries such as Kavir Steel Company, as well as changes in the agricultural and rural landscape, an increase in urbanization phenomena, the expansion of cities and the correctness of the research hypothesis can be confirmed. In fact, in the south of the study area, there is a collection of small villages, and their small traditional agricultures exist without significant land-use change, while the northern part of the study area, as it was explained (see Section 3.1), is known as a developed area due to the existence of large industries, cities and commercial agriculture. However, the sensitivity of desertification in the northern zone is more severe than in the undeveloped zone. So, on the same climatic conditions, land-use change is one of the most influential factors in reducing or increasing the risk of desertification in the study area. 


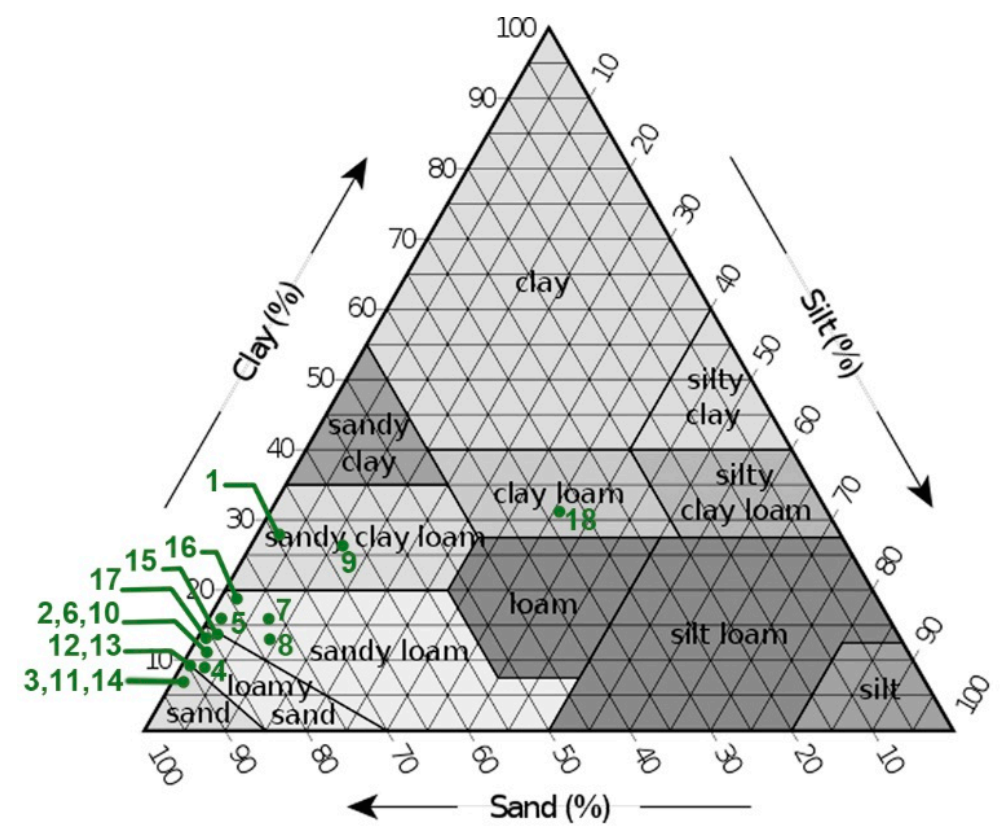

Figure 14. The result of the soil texture test.

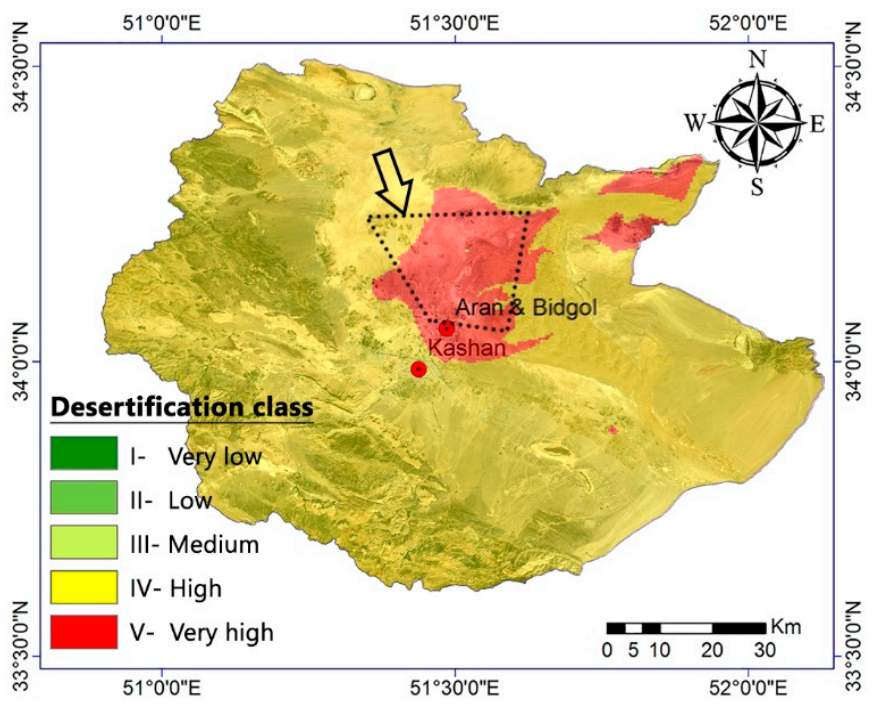

Figure 15. Classification of sensitivity to desertification. Arrow, the study area.

Based on these findings, this research focuses on the more problematic area, which is the area around the small settlements of Noush Abad and Aran Bidgol, to find a sustainable model for combating desertification. In this way, three scenarios have been suggested.

\subsection{Probable Future of Landscape in Three Scenarios}

\subsubsection{Scenario 1: Evolution of Current Conditions}

The first scenario is based on existing long-term plans in the study area and the analysis of their strengths and weaknesses.

(I) In "Comprehensive planning-2013", the remote villages have been completely ignored. The distance from main urban centers and related services is reinforcing a migration process from small villages to cities (Table 4; Figure S3). In this way, a large part of the county will be abandoned, and the entire population of the county will be concentrated in a small area. The abandonment of land, as a global problem with environmental implications, increases the risk of land degradation and desertification [44]. 
(II) "Tourism routes planning -2011" aims to increase revenue for the region's indigenous people through tourism. Seven tourist routes, which often start from mountainous areas in Kashan county and end at Maranjab Caravanserai in Aran-Bidgol county, are designed (Figure S4). Despite its many advantages and strengths, this project also has its weaknesses. Many tourists must enter the area in autumn and spring, which will damage the environment and vegetation of the area. In addition, tourists' favorite pastimes, such as skiing on the sand, safaris, and car racing on sand dunes, increase soil erosion. Another criticism of the project is its disregard for other cultural potentials as tourist attractions.

(III) Finally, we evaluated the "Afforestation plan". According to UNCCD (United Nations Convention to Combat Desertification), "Afforestation is the planting of trees or forest cover on land which historically did not contain forests" [45]. In Iran, the project of biological stabilization of sand dunes began in 1963. For the first time, it was tested on the sand dunes near Abuzeid-Abad city, in Aran-Bidgol county, and it had great success [46]. The project, originally intended only for the establishment of sand dunes, has expanded over time as a green belt. The main aims are: soil stabilization, increasing shade and soil moisture, reducing soil erosion, windbreak function [47]. Today, this project is underway even near the qanats (Figure 16). Because of the deep and extensive "roots of trees that can intensify the tunnel crumbling of qanats" and cause irreparable damage to this valuable cultural heritage, "the qanat masters do not recommend planting the trees" [48].

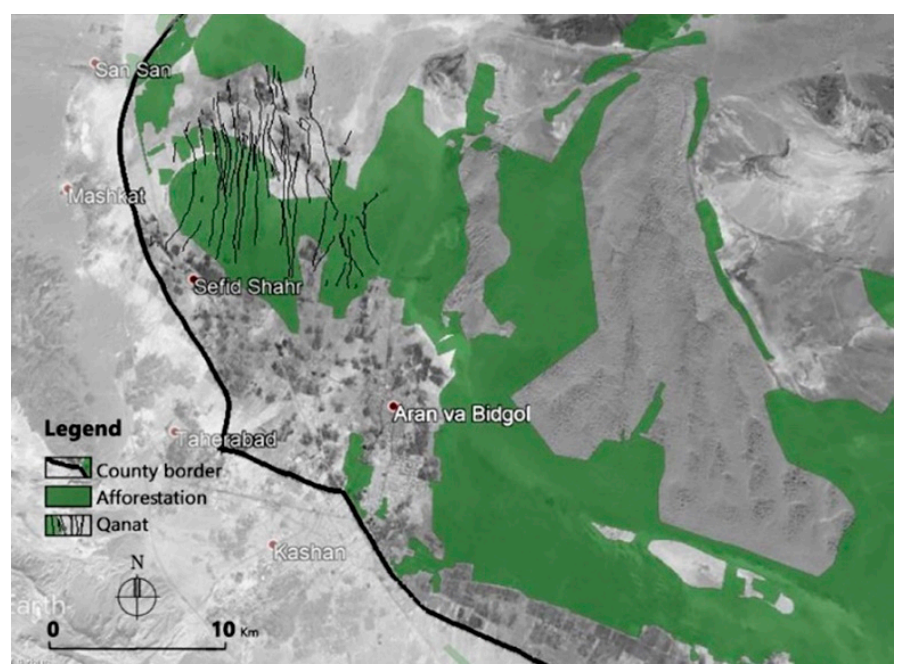

Figure 16. Zones of biological stabilization by planting Haloxylon trees (GIS information received in 2019 from the department of natural resources and watershed management of Aran-Bidgol county).

Based on the first scenario evaluation, severe landscape changes will occur at the expense of small villages and family farms. Furthermore, the increase in migration, traditional knowledge oblivion, the increase in barren lands and the lack of recharge groundwater aquifers will result in soil and water erosion and the intensification of desertification phenomena.

\subsubsection{Scenario 2: Reconstruction of the Past}

The second scenario is based on the resettlement of rural areas by the preservation and restoration of existing cultural heritage. It would be possible to try to create a new direction of migration from upstream oases to downstream oases (reverse migration) and provide opportunities for villagers to return to their homeland by reactivating agriculture. It is important to note that digging new wells is not allowed in this county (Figure 7). Therefore, as a first step, the water required for agriculture in secondary oases should be supplied from a source other than deep wells. Today, one of the sources of water supply is water reuse, and several studies are being performed to facilitate wastewater treatment 
and reduce its costs. "In arid and semi-arid areas recycling of water may have a greater impact on future usable water supply than any of the other technologies aimed for increasing water supply. Treated sewage water can be used for irrigation, industry, recharge of groundwater, and in special cases, properly treated wastewater can be used for municipal supply" [49]. By injecting treated municipal and industrial wastewater into the upstream areas, it is expected that the aquifer will be recharged and the qanat system will be reactivated.

This scenario implies the problem of dealing with the quality of agricultural soil. The results of soil analysis indicate high salinity in sandy soils (Table S2). With proper water and soil management, and the simultaneous use of innovative technology and indigenous knowledge, it would be possible to refunctionalize agriculture and counteract immigrated villagers, on the assumption of rebuilding the villages which are at present destroyed or not livable.

Positive feedback would be: the interruption of water extraction through deep wells, recharging groundwater aquifers, water quality control, and the protection of qanats against destructive factors. By contrast, huge initial investments would be required.

\subsubsection{Scenario 3: New-Traditional Spatial Configuration}

The new configuration of rural and agricultural landscapes in scenario 3 tries to take into account the integrated landscape management approach $[50,51]$ and accordingly addresses the needs of the rural community, such as health and welfare, as well as cultural and natural values of the landscape.

Scenario 3 is based on the reorganization of the rural and agricultural landscape as a barrier against desertification by oasification and creating new oases in the area with a high sensibility to desertification. Oasification is an approach to overcome desertification hazards, "which is implemented by land use and environmental management and engineering measures to reach desert and oasis landscape sustainability" and "the oasification process improves the condition of soil and water, increases the vegetation cover, and provides the habitats for wildlife and human beings" [52]. To achieve this aim and present future patterns, landscape zones were identified based on geomorphology, vegetation, land use and traditional management, according to the following definition: "Landscape zones are a framework for displaying the current status and they are a tool for presenting future landscape narratives [53]."

Three main homogeneous zones were determined for oasification and spatial configuration using new-traditional methods (Figure 17):

1- Traditional agricultural areas on the sand dunes, as a multifunctional agriculture space of high potential for agri-tourism;

2- The axis that connects urban areas to remote villages, as a suitable area to insert: (a) the new oases for a better distribution of the population, and (b) a green barrier in the form of a multifunctional productive landscape;

3- The cultural and historical areas composed of the abandoned villages and qanats, as a neo-traditional landscape divided into three parts: (a) phytodepuration ponds to recharge the aquifer (low-tech and low-cost); (b) the qanat area as a cultural heritage to be preserved and integrated with technological innovation (e.g., photovoltaic park); the replacement of abandoned villages and degraded agricultural land with land-uses less sensitive to water quality (e.g., cultivation of specific plants for foraging, grazing). The resulting landscape masterplan design is reported in Figure 18. 


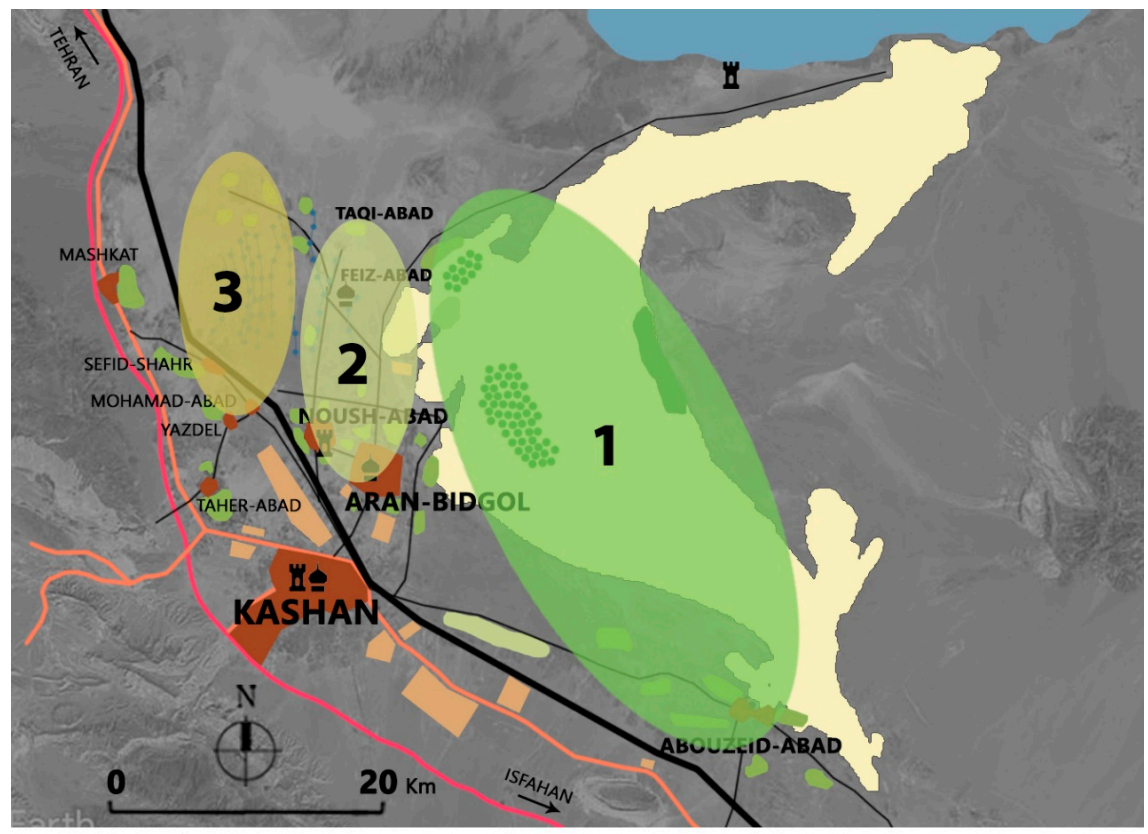

\section{Legend}

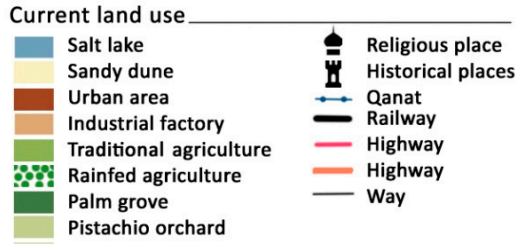

Figure 17. Landscape zonation in the study area.

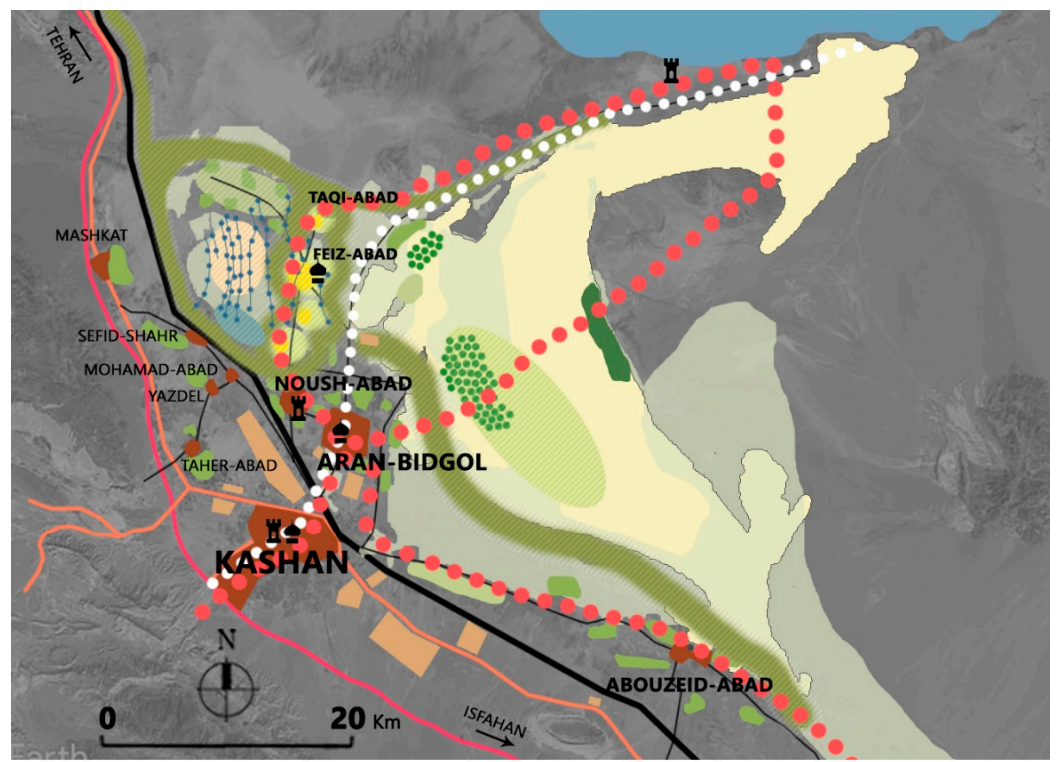

Legend

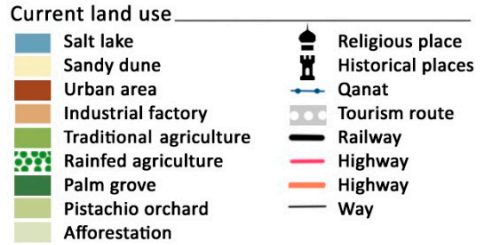

Suggested zones

1 Multifunctional agriculture area

2 New Oases

3 Neo-traditional landscapes 
This scenario will allow the connection of natural and cultural capital [54] by creating, at the same time, an innovative and complex green belt consisting of:

- Multifunctional agriculture;

- Productive green windbreaks instead of Haloxylon afforestation (afforestation limited only to places where a windbreak function is necessary);

- Eco-friendly new oases (water treatment and watershed management projects; research farms, eco-camping, solar farms);

- A regenerated economy (industries related to agriculture and animal husbandry, industries related to indigenous knowledge (e.g., in the study area, handmade carpets have a long history, so relevant industries such as dyeing and spinning are justified)).

An agro-eco-tourist route connects all components of this neo-traditional greenbelt (Figure 18).

Therefore, in this proposal, the green belt will be a set of land uses that interact with each other and are managed following the integrated landscape management approach. The proposed green belt is a unified system of small-scale projects, most of which are funded and implemented with the participation of local society and in accordance with the Sustainable Development Goals (SDGs) [55].

\section{Conclusions}

The inharmonious development of the landscape eliminates its special distinctive features and creates a gap between people and their past. The urbanization process not only tears up the agricultural and semi-natural landscapes to pieces, but it also eliminates the mosaic diversity of traditional landscapes. Today, rural and agricultural landscapes are shrinking all over the world due to the threat of uncontrolled urban and suburban expansion and agriculture abandonment. Consequently, new groups enter the landscape who do not have enough awareness of traditional practices; therefore, the sense of belonging to the landscape is reduced and participation in landscape management also reduces. The derived desertification increases poverty and migration.

In arid and semi-arid regions, the long-term results of afforestation projects show that they are actually increasing environmental degradation, with ecosystems deteriorating. From 2007, instead of a wall of trees, a new concept of green belt was launched, which consists of a mosaic of sustainable land management approaches to provide long-term solutions for restoring landscapes and improving livelihoods.

The study area represents an emblematic case of the phenomenon described above: an area on the edge of the desert, with a system of abandoned oases characterized by agricultural organization, settlement and the use of traditional agricultural resources that have undergone the influences of industrialization and are in decline due to the advancement of the phenomenon of desertification. Faced with this condition and the various possible intervention alternatives such as maintaining the current trend or a vernacular attitude of restoring important traditional systems, this study proposes an original intervention that combines the knowledge of tradition with the opportunities of contemporary research, and outlines a possible and repeatable strategy. The proposed scenario is to create a new traditional green area that includes small low-cost and low-tech projects adapted to the rural scale.

It is expected that with the realization of this idea, rural-urban migration will decrease, and with the establishment of immigrants in new oases, rural and agricultural areas will be developed sustainably with the participation of local people. Due to maintaining the population balance in the region and containing the population of cities, the management of urban services will also be improved, thus the main stakeholders of the project, in addition to villagers and farmers, also include urban residents. Furthermore, with the increase in multifunctional agriculture, it is expected that this will ensure food security and quality, improve environmental conditions, and reduce the need for industrial jobs. 
The proposed method of analysis and the adopted approach for an ecological landscape design represent a pilot methodology suitable to be applied in other situations, transforming it into a strategy to limit the progress of desertification.

Supplementary Materials: The following are available online at https://www.mdpi.com/2071-1 050/13/4/2077/s1, Table S1: Summary of water quality test; Table S2: Summary of soil quality test; Figure S1: The topography of the county Aran-Bidgol; Figure S2: Age-gender-pyramid of Aran-Bidgol county; Figure S3: Service facilities' spheres of influence evaluation; Figure S4: Proposed Tourist routes to Maranjab Desert.

Author Contributions: R.B. and M.S. conceived the research design; M.S. collected and processed the empirical data, masterplan, and software; R.B., L.V.F. and M.S. carried out the literature analysis, interpreted the empirical results of the research, and wrote the whole manuscript; all photos credit: M.S. All authors have read and agreed to the published version of the manuscript.

Funding: This research received no external funding.

Institutional Review Board Statement: Not applicable.

Informed Consent Statement: Not applicable.

Data Availability Statement: The data presented in this study are available in the article and supplementary material.

Acknowledgments: Ph.D. research (Ph.D. program in Landscape and Environment) co-funded by Sapienza, University of Rome (Italy). The authors would like to thank Fabio Di Carlo for support during the Ph.D. program. Mahnaz Sarlak is grateful to all Iranian institutions and all persons that helped her to collect the data.

Conflicts of Interest: The authors declare no conflict of interest.

\section{References}

1. Patel, K.; Gartaula, H.; Johnson, D.; Karthikeyan, M. The interplay between household food security and wellbeing among small-scale farmers in the context of rapid agrarian change in India. Agric. Food Secur. 2015, 4, 16. [CrossRef]

2. Li, C.; Lei, J.; Zhao, Y.; Xu, X.; Li, S. Effect of saline water irrigation on soil development and plant growth in the Taklimakan Desert Highway shelterbelt. Soil Tillage Res. 2015, 146, 99-107. [CrossRef]

3. Ghanbarpour, M.R.; Ahmadi, E.; Gholami, S. Evaluation of different traditional water management systems in semi-arid regions (case study from Iran). Options Méditerranéennes Série B Etudes Rech. 2007, 3, 133-139.

4. Saboohi, R.; Barani, H.; Khodagholi, M.; Sarvestani, A.A.; Tahmasebi, A. Nomads' indigenous knowledge and their adaptation to climate changes in Semirom City in Central Iran. Theor. Appl. Clim. 2018, 137, 1377-1384. [CrossRef]

5. Verón, S.; Paruelo, J.; Oesterheld, M. Assessing desertification. J. Arid. Environ. 2006, 66, 751-763. [CrossRef]

6. Yan, X.; Cai, Y.L. Multi-Scale Anthropogenic Driving Forces of Karst Rocky Desertification in Southwest China. Land Degrad. Dev. 2015, 26, 193-200. [CrossRef]

7. Barrios, S.; Bertinelli, L.; Strobl, E. Climatic Change and Rural-Urban Migration: The Case of Sub-Saharan Africa. J. Urban Econ. 2006, 60, 357-371. [CrossRef]

8. Madanipour, A. Urban planning and development in Tehran. Cities 2006, 23, 433-438.

9. Mirzayi, J.; Peyvastegar, Y.; Kalantari, H. Presenting the Exploratory-Experimental Model of Factors Inhibiting the Realization of Urban Comprehensive Plans (Case Study: Shiraz Metropolis). Hum. Geogr. Res. 2020, 52, 1391-1408.

10. Farhoodi, R.; Gharakhlou, N.M.; Ghadami, M.; Khah, M.P. A Critique of the Prevailing Comprehensive Urban Planning Paradigm in Iran: The Need for Strategic Planning. Plan. Theory 2009, 8, 335-361.

11. Darkoh, M.B.K. The nature, causes and consequences of desertification in the drylands of Africa. Land Degrad. Dev. 1998, 9, 1-20. [CrossRef]

12. Goffner, D.; Sinare, H.; Gordon, L.J. The Great Green Wall for the Sahara and the Sahel Initiative as an opportunity to enhance resilience in Sahelian landscapes and livelihoods. Reg. Environ. Chang. 2019, 19, 1417-1428. [CrossRef]

13. Saley, I.A.; Salack, S.; Sanda, I.S.; Moussa, M.S.; Bonkaney, A.L.; Ly, M.; Fodé, M. The possible role of the Sahel Greenbelt on the occurrence of climate extremes over the West African Sahel. Atmos. Sci. Lett. 2019, 20, e927. [CrossRef]

14. Cao, S. Why Large-Scale Afforestation Efforts in China Have Failed to Solve the Desertification Problem; ACS Publications: Washington, DC, USA, 2008.

15. Medugu, N.I.; Majid, M.R.; Johar, F.; Choji, I. The role of afforestation programme in combating desertification in Nigeria. Int. J. Clim. Chang. Strat. Manag. 2010, 2, 35-47. [CrossRef] 
16. Beiser, V. China's Green Great Wall is on the Front Line of Its Fight against Desertification, but Is It Sustainable? 2018. Available online: https:/ / www.scmp.com/magazines/post-magazine/long-reads/article/2177586/chinas-green-great-wall-front-lineits-fight (accessed on 20 May 2020).

17. Ceci, P.; Sanogo, S.; Ambrose, E.; Sacande, M.; Sanou, L.; Adda, M.; Ulian, T. SDG 15: TARGET 15.3 REVERSING LAND DEGRADATION AND DESERTIFICATION IN AFRICA'S DRYLANDS. BGjournal 2018, 15, 19-22.

18. F.A.O. Great Green Wall. Available online: http:/ /www.fao.org/in-action/action-against-desertification/overview/great-greenwall/en/ (accessed on 26 May 2020).

19. Luengo, M. Looking ahead: The olive grove cultural landscape. In Proceedings of the ICOMOS 17th General Assembly, Paris, France, 27 November 2011; 2012; pp. 623-630. Available online: http:/ / openarchive.icomos.org/id/eprint/1257/1/III-2-Article9 _Luengo.pdf (accessed on 15 March 2019).

20. Bonine, M.E. The morphogenesis of iranian cities*. Ann. Assoc. Am. Geogr. 1979, 69, 208-224. [CrossRef]

21. English, P.W. The origin and spread of qanats in the Old World. Proc. Am. Philos. Soc. 1968, 112, $170-181$.

22. English, P.W. Qanats and lifeworlds in Iranian plateau villages. Yale F ES Bull. 1998, 103, 187-205.

23. De Cesaris, A.; Di Giorgio, G.; Ferretti, L.V. Attraverso l'Iran. Citta, Architetture, Paesaggi; no. 1; Manfredi edizioni: Macerata, Italy, 2017.

24. Jafary, F.; Bradley, C. Groundwater irrigation management and the existing challenges from the farmers' perspective in Central Iran. Land 2018, 7, 15.

25. Johnston, R.J. The dictionary of human geography. In The Dictionary of Human Geography; Basil Blackwell: Oxford, UK, 1981; p. 718.

26. ach, J.; Szczepańska, B. Contemporary Directions of Transformations in the Settlement and the Landscape of Rural Areas in the Silesian Lowland. Quaest. Geogr. 2020, 39, 55-73. [CrossRef]

27. Antrop, M. Why landscapes of the past are important for the future. Landsc. Urban Plan. 2005, 70, 21-34. [CrossRef]

28. Naveh, Z. From biodiversity to ecodiversity-holistic conservation of the biological and cultural diversity of Mediterranean landscapes. In Landscape Disturbance and Biodiversity in Mediterranean-Type Ecosystems; Springer: New York, NY, USA, 1998; pp. 23-53.

29. Biasi, R.; Brunori, E.; Smiraglia, D.; Salvati, L. Linking traditional tree-crop landscapes and agro-biodiversity in central Italy using a database of typical and traditional products: A multiple risk assessment through a data mining analysis. Biodivers. Conserv. 2015, 24, 3009-3031.

30. Bestelmeyer, B.T.; Okin, G.S.; Duniway, M.C.; Archer, S.R.; Sayre, N.F.; Williamson, J.C.; Herrick, J.E. Desertification, land use, and the transformation of global drylands. Front. Ecol. Environ. 2015, 13, 28-36. [CrossRef]

31. Thornes, J.; Brandt, C.J. Mediterranean Desertification and Land Use; Wiley Chichester: Chichester, UK, 1996.

32. Ekhtesasi, M.R. How to Classify Desertification in Iran; Research Institute of Forests and Rangelands: Tehran, Iran, 1996.

33. Abad, J.R.S.; Nohegar, A.; Zehtabian, G.; Khosravi, H.; Gholami, H. Study of desertification status based on a sub-IMDPA model for a case study in Yazd-Ardakan plain, Iran. Int. J. For. Soil Eros. 2016, 6, 73-81.

34. UNRCS. Soil survey division staff (1993) soil survey manual. Soil conservation service. US Dep. Agric. Handb. $1993,18,315$.

35. Shearer, A.W. Approaching Scenario-Based Studies: Three Perceptions about the Future and Considerations for Landscape Planning. Environ. Plan. B Plan. Des. 2005, 32, 67-87.

36. Shirehpaz, A. Aran and Bidgol: Jewel of Central Desert of Iran; Maranjab: AranBidgol, Iran, 2018.

37. Majd, M.G. Land Reform Policies in Iran. Am. J. Agric. Econ. 1987, 69, 843-848. [CrossRef]

38. Gleeson, T.; Vandersteen, J.; Sophocleous, M.A.; Taniguchi, M.; Alley, W.M.; Allen, D.M.; Zhou, Y. Groundwater sustainability strategies. Nat. Geosci. 2010, 3, 378-379. [CrossRef]

39. Kardavani, P. The Problems of Waters in Iran, 10th ed.; University of Tehran Press: Tehran, Iran, 2011.

40. Satterthwaite, D.; McGranahan, G.; Tacoli, C. Urbanization and its implications for food and farming. Philos. Trans. R. Soc. B Biol. Sci. 2010, 365, 2809-2820. [CrossRef]

41. Plieninger, T.; Höchtl, F.; Spek, T. Traditional land-use and nature conservation in European rural landscapes. Environ. Sci. Policy 2006, 9, 317-321.

42. Altieri, M.A. Linking Ecologists and Traditional Farmers in the Search for Sustainable Agriculture. Front. Ecol. Environ. 2004, 2, 35-42. [CrossRef]

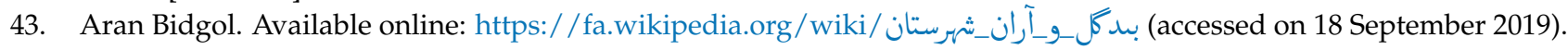

44. Kosmas, C.; Kairis, O.; Karavitis, C.; Acikalin, S.; Alcala, M.; Alfama, P.; Atlhopheng, J.; Barrera, J.; Belgacem, A.; Solé-Benet, A.; et al. An exploratory analysis of land abandonment drivers in areas prone to desertification. Catena 2015, 128, 252-261. [CrossRef]

45. UNCCD. Sustainable Land Management Contribution to Successful Land-based Climate Change Adaptation and Mitigation; UNCCD: Bonn, Germany, 2017.

46. Kardavani, P. The Great Central Kawir of Iran, 2nd ed.; University of Tehran Press: Tehran, Iran, 2008.

47. Jin, Z.-Z. Soil microbial variation and relationship with soil environmental factors in the desert hinterland greenbelt. Chin. J. Eco-Agriculture 2008, 16, 1358-1364. [CrossRef]

48. Yazdi, A.A.S.; Khaneiki, M.L. Qanat Maintenance and Preservation. In Qanat Knowledge; Springer: Dordrecht, The Netherlands, 2017; pp. 117-143. 
49. Hamdy, A. Irrigation with treated municipal wastewater. In Prospett. e Propos. Mediterr. di Econ. Agric. e Ambient; Bari, Italy, 1992; 1/92, 50-54. Available online: http://www.iamb.it/share/img_new_medit_articoli/549_50hamdy.pdf (accessed on 25 October 2019).

50. García-Martín, M.; Bieling, C.; Hart, A.; Plieninger, T. Integrated landscape initiatives in Europe: Multi-sector collaboration in multi-functional landscapes. Land Use Policy 2016, 58, 43-53.

51. Mann, C.; Garcia-Martin, M.; Raymond, C.M.; Shaw, B.J.; Plieninger, T. The potential for integrated landscape management to fulfil Europe's commitments to the Sustainable Development Goals. Landsc. Urban Plan. 2018, 177, 75-82. [CrossRef]

52. Xue, J.; Gui, D.; Lei, J.; Sun, H.; Zeng, F.; Mao, D.; Jin, Q.; Liu, Y. Oasification: An unable evasive process in fighting against desertification for the sustainable development of arid and semiarid regions of China. Catena 2019, 179, 197-209. [CrossRef]

53. Makhzoumi, J.; Talhouk, S.; Zurayk, R.; Sadek, R. Landscape approach to bio-cultural diversity conservation in rural Lebanon. In Perspectives on Nature Conservation-Patterns, Pressures and Prospects; Intech: Rijeka, Croatia, 2012; pp. 179-198.

54. Paracchini, M.L.; Zingari, P.C.; Blasi, C. Reconnecting Natural and Cultural Capital; Publication Office of the European Union: Luxembourg, 2018; p. 253.

55. Sarlak, M. Agricultural Landscape of the Sandy Desert in Iran. Ph.D. Thesis, Sapienza University of Rome, Rome, Italy, 2020. 